Received: November 21, 2017

Revision received: March 22, 2018

\title{
Research on Teaching Strategies of Sports Translation Based on Neurocognitive Science
}

\author{
Xiaoxuan $\mathrm{Jia}^{1}$ \\ Hebei Agricultural \\ University \\ Zhonghua Liu $^{4}$ \\ Bohai Campus \\ Hebei Agricultural University
}

\author{
Yimeng Fan $^{2}$ \\ Hebei Agricultural \\ University \\ Min $\mathrm{Chao}^{5}$ \\ Bohai Campus Hebei \\ Agricultural University
}

\author{
Shiqi $\mathrm{Hu}^{3}$ \\ Bohai Campus \\ Hebei Agricultural University \\ Mingqiang Zhang ${ }^{6}$ \\ Hebei Agricultural University
}

\begin{abstract}
In order to meet the needs of social development and explore the teaching strategies that meet the needs of sports translators, this paper focuses on the sports translation teaching strategies, the research objective of this paper, using literature research methods, case studies, and questionnaire, based on the analysis of the status quo of sports translator talents and combined with brain science and its research results in the field of education. The present research puts forward the whole brain teaching strategies of sports translation, expounds the concrete contents of the teaching strategies, and conducts the investigation and analysis of the implementation effects of sports translation teaching strategies based on neurocognitive science taking the basketball item in the course of Sports English as an example. The results show that the strategies of sports translation teaching based on neurocognitive science has a certain guiding role in improving the effectiveness of sports translation teaching.
\end{abstract}

\section{Keywords}

Neurocognitive Science $\bullet$ Whole Brain Teaching Strategies $\bullet$ Sports Translation $\bullet$ Teaching Effect

\footnotetext{
${ }^{1}$ Department of Sports Works, Hebei Agricultural University, Baoding 071000, China. Email: mingrass@ 126.com ${ }^{2}$ Department of Sports Works, Hebei Agricultural University, Baoding 071000, China. Email: fanyimeng@126.com ${ }^{3}$ Department of Basic Courses, Bohai Campus-Hebei Agricultural University, Huanghua 061100, China. Email: hushiqi1973@163.com

${ }^{4}$ Department of Basic Courses, Bohai Campus- Hebei Agricultural University, Huanghua 061100, China. Email: 164316012@qq.com

${ }^{5}$ Department of Basic Courses, Bohai Campus- Hebei Agricultural University, Huanghua 061100, China. Email: 574365175@qq.com

${ }^{6}$ Correspondence to: Mingqiang Zhang, Department of Sports Works, Hebei Agricultural University, Baoding 071000, China. Email: tyqiang7521569@163.com
}

Citation: Jia, X. X., Fan, Y. M., Hu, S. Q., Liu, Z. H., Chao, M., \& Zhang, M. Q. (2018). Research on Teaching Strategies of Sports Translation Based on Neurocognitive Science. Educational Sciences: Theory \& Practice, 18(5), 2295-2305. http://dx.doi.org/10.12738/estp.2018.5.128 
In recent years, with the booming sports industry in China, especially the successful hosting of the 2008 Beijing Olympic Games, China have seen more major sports events and more frequent foreign sports exchanges in a world with internationalization and integration of sports, leading to an increasing demand of high-level sports translation talents in China. However, the investigation and analysis show that the quantity and quality of sports translation talents cannot meet the needs at present, which puts forward the urgent demand for the training of sports translation talents in China.

Sports translation practitioners are required not only to master the foreign languages, but also sports, specifically, the professional terms, terminology and competition rules (Esteban, 1980). English is one of the international languages, thus English translation in sports can basically meet all kinds of sports translation work. Therefore, it is of great significance to strengthen the English knowledge learning of sports professional personnel for cultivating sports translation talents. Classroom teaching is the main position for cultivating sports translation talents. Thus, how to effectively design and use classroom teaching to improve students' listening, speaking, reading, writing and translation capabilities (Singh, 1993) is the key to cultivating specialized sports translation talents that meet the needs of the sports industry.

As early as 1978, some scholars first explored brain-based English teaching, and proposed using the imagination method in English teaching (Timothy, 2006). Later, some scholars have put forward the relationship between neurolinguistics and foreign language teaching, and use audiovisual methods to improve learners' ability to learn a foreign language (Göknar, 2004). Some scholars propose that there is a dual structure in the learner's brain in foreign language learning, so we should develop the function of the right brain in foreign language learning, and increase the use of computer-aided teaching in English learning (Simonton, 2008).

Based on the above analysis, this paper attempts to study the teaching strategies of sports translation from the perspective of neurocognitive science. The present study summarizes the knowledge composition necessary for sports talents based on the investigation and analysis of the status quo of sports translation talents, puts forward four kinds of whole brain teaching strategies that are suitable for sports translation combining the previous theories of brain science and education, and designs and implements the strategies using Sports English as an example. Through comparative experiments, this study verifies that these teaching strategies have certain effects in promoting sports translation teaching, which provides a new reference for sports translation teaching and has certain practical significance.

\section{Survey and analysis of status quo of sports translation talents}

\section{Sports translation talents}

Sports translation talents (Anderson, 1997) refer to international and general foreign language talents who can use one or more foreign languages for sports service based on their professional knowledge of sports and international conventions and have strong abilities for language application and information processing. Figure 1 shows the specific classification of sports translation (Fissler, Kolassa, \& Schrader, 2015; CAPT 2018). 


\section{Survey and analysis of status quo of sports translation talents}

Professional background and language skills

According to the professional background survey, most sports translation talents in China come from sports majors and foreign language majors, as shown in Figure 2. The survey results in Figure 3 show that the proportion of sports translators good at English translation accounts for up to $91 \%$, which is due to the fact that English is an international universal language, suggesting that Sports English translation can basically meet all kinds of sports translation work. Therefore, it is of great significance to strengthen the English knowledge learning of sports professional personnel for cultivating sports translation talents.

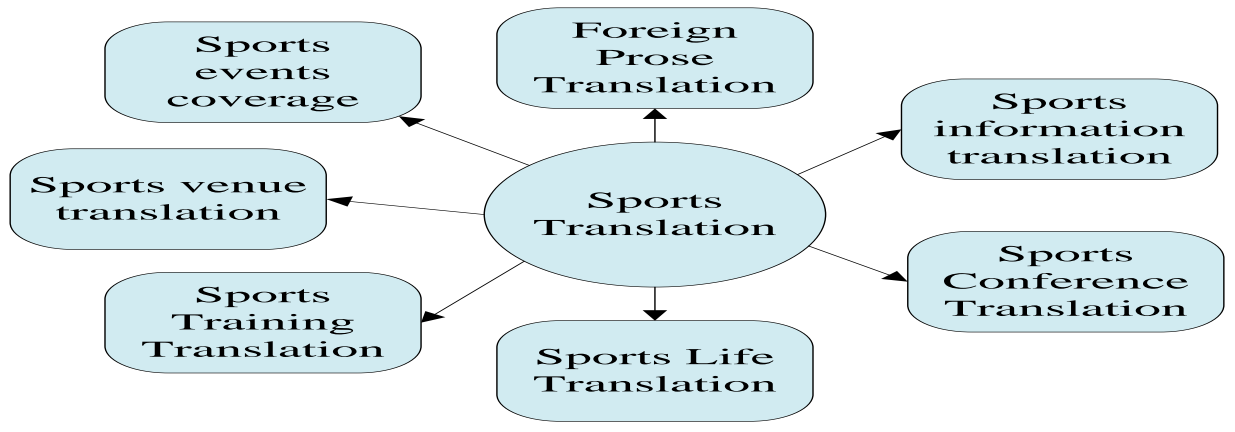

Figure 1. Sports translation category

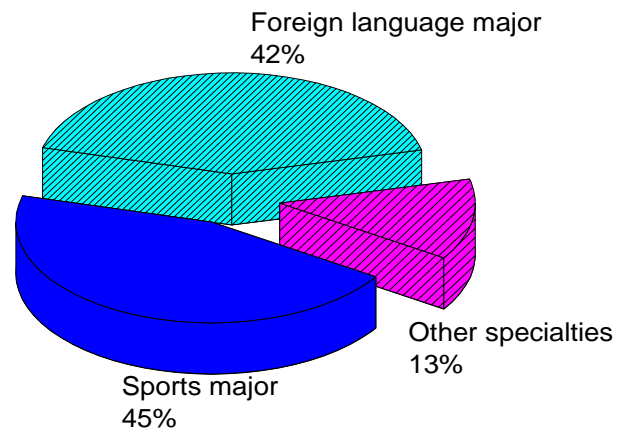

Figure 2. Professional background distributions

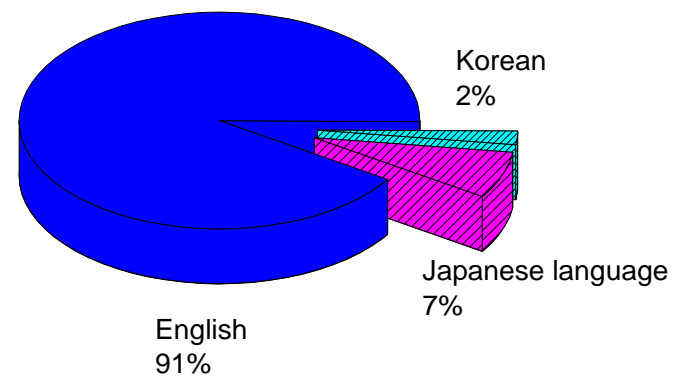

Figure 3. Good at language distribution 
Jia, Fan, Hu, Liu, Chao, Zhang / Research on Teaching Strategies of Sports Translation Based on Neurocognitive Science.

External and self-evaluation of job satisfaction

According to a survey on sports industry associations, event organizers and individual sports translators, about $59 \%$ of the outsiders are relatively satisfied or very satisfied with sports translation work, and $5.9 \%$ are dissatisfied, while $88 \%$ of sports translators are satisfied with their translation work and 0 is not satisfied, as shown in Figure 4. According to the survey results, it can be known that sports translators are more confident in their own work, but there is still a certain gap compared with the social needs, indicating that the translation quality still needs to be improved.

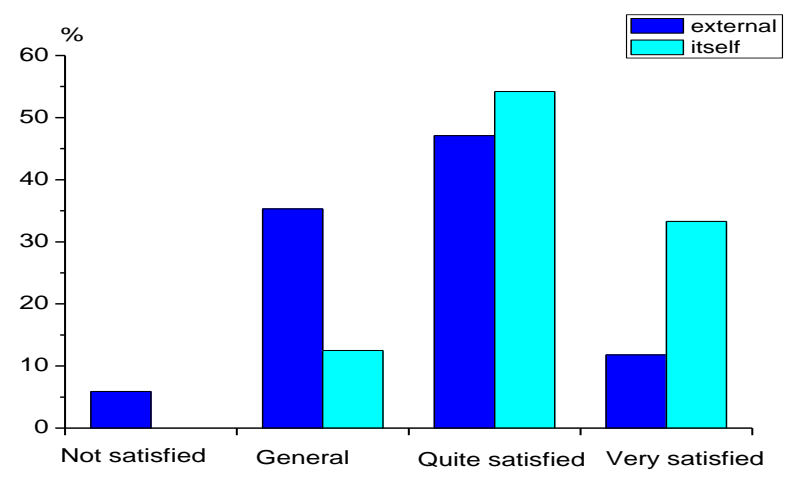

Figure 4. External and self-evaluation of job satisfaction

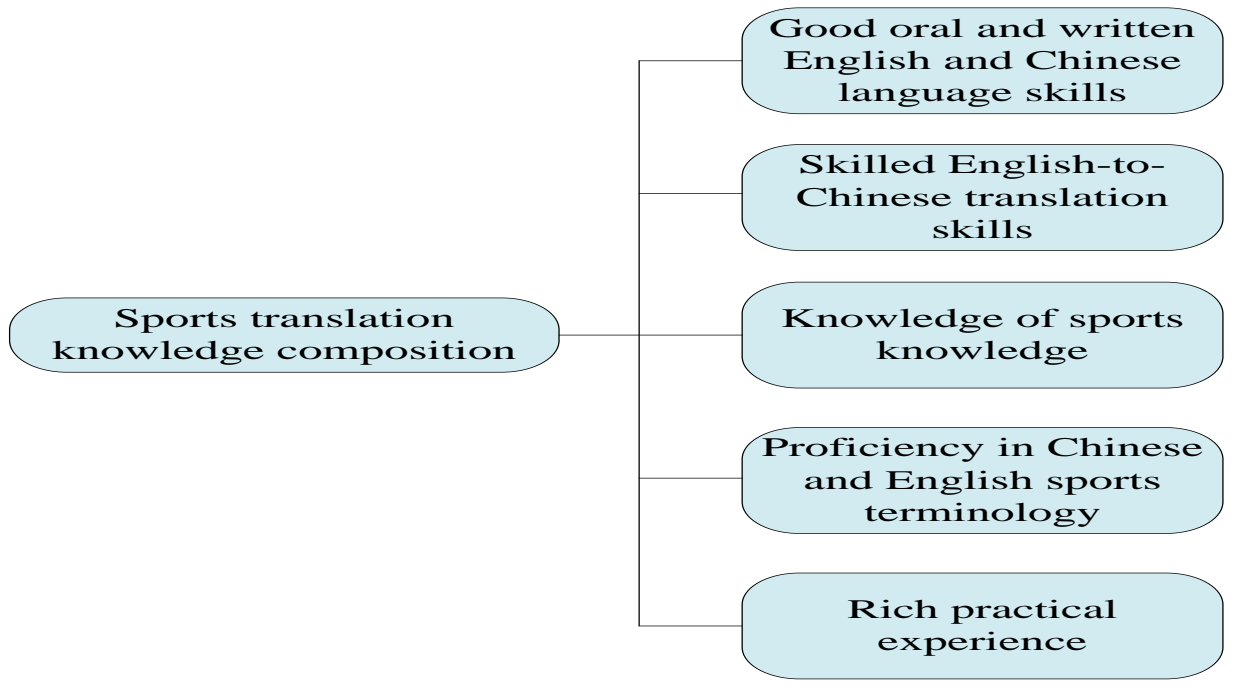

Figure 5. The basic knowledge that sports translation should have

Knowledge background for sports translation

Through investigations, it has also been learned that the learning of mother tongue is also very important for sports translation other than proficiency in foreign language and sports related knowledge, so as to achieve 
Jia, Fan, Hu, Liu, Chao, Zhang / Research on Teaching Strategies of Sports Translation Based on Neurocognitive Science.

$\overline{\text { fidelity, expressiveness and elegance in translation, avoiding mistakes. Figure } 5 \text { shows the basic knowledge }}$ composition necessary for sports translation concluded through investigations (Anderson, 2010).

Through the above investigation and analysis, it is found that Sports English translation talents present a major demand in the society, but at present the level of sports translation has yet to be improved. Colleges and universities are the main positions for cultivating talents, and classroom teaching is the main way for students to acquire knowledge and ability. Therefore, it is of great significance for improving the quality of sports translation talents by designing classroom teaching activities in light with students' cognition based on the needs of society.

\section{Teaching strategies of sports translation based on neurocognitive science}

\section{Whole brain teaching strategies}

Learning is the process of mobilizing the left and right brains (Antonini et al., 2013), so education cannot be separated from the cognition and mastery of the brain. Only through the understanding of the structure and functions of the brain can the two thinking modes of the left and right brain be better integrated in the teaching. Figure 6 shows the division of the left and right brains (Carlo, 2013). Although the left brain is believed to be the key brain area for language learning for a long time, there are also studies showing that the right brain plays a vital role in the learning of a second language. Therefore, the teaching of the whole brain should be paid more attention to in language learning (Needham, GweiDjen, \& Porkert, 1975).

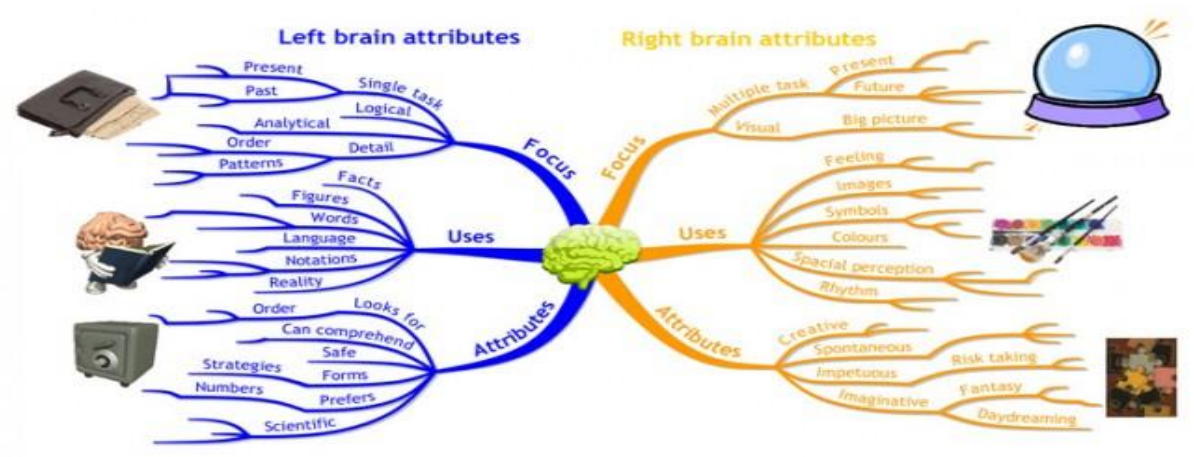

Figure 6. Left and right brain division diagram

Teachers should pay attention to the alternating use of hearing and vision when adopting the whole brain teaching strategies. That is, the traditional lecturing shall be supported with pictures, video and other forms to strengthen the stimulation of the vision, so that students can use their intuitive thinking and logical thinking alternately to arouse their knowledge memorization.

Table 1 shows the preferential teaching strategies of left and right brains (Mckibbon et al., 2013). Combined with the characteristics of sports English translation, this paper proposes the following four kinds of brain-based intelligent teaching strategies related to the teaching of sports English translation (Weaver, \& Chelladurai, 1999). 
Jia, Fan, Hu, Liu, Chao, Zhang / Research on Teaching Strategies of Sports Translation Based on Neurocognitive Science.

(1) Interpersonal intelligence-based strategies (Borsa et al., 2005). It emphasizes the ability to cooperate with others and develops students' ability to observe and analyze other people's thoughts, movements, and emotions. The translation-related tasks (such as commentary and translation materials) are accomplished through group discussion and co-writing, which can promote the realization of cooperative learning and create a good learning atmosphere.

(2) Bodily-kinesthetic intelligence-based strategies. Teachers create situations on class, allowing students to complete their knowledge learning through hands-on experience by means of role-play or situational dialogues, thus to strengthen their listening, speaking, reading, writing, and translation skills.

(3) Visual-spatial intelligence-based strategies. Teachers present the teaching content to students visually using video, graphics, and other forms. For example, teachers can show sports related pictures to students and ask them to describe them in English according to the picture content, thus enabling students to deepen their knowledge memorization.

(4) Self-reflective intelligence-based strategies (Katan, 2009). It emphasizes the cultivation of self- cognitive and reflective abilities. Teachers can develop students' self-reflective ability by asking students to compare their translations with the live translations on the field or to listen to celebrity interviews. This can also cultivate students' autonomous leaning abilities.

In order to better implement the whole brain teaching strategies, teachers should start from the following aspects when designing teaching activities (Grenier, 2007).

Table 1

Left and Right Brain Preferences Teaching Strategies

\begin{tabular}{|c|c|c|}
\hline- & Hemisphere preference & Teaching strategies \\
\hline \multirow{8}{*}{ Left brain preference } & More like ordered things & \multirow{8}{*}{$\begin{array}{l}\text { 1. Reports related to teaching } \\
\text { materials } \\
\text { 2. Inspire multiple sensory channels } \\
\text { 3. Use metaphor } \\
\text { 4. Encourage students to set goals } \\
\text { 5. Inspire logical thinking }\end{array}$} \\
\hline & Efficient classroom organization & \\
\hline & Learn better from part to whole & \\
\hline & More like voice reading system & \\
\hline & Would rather read the topic first & \\
\hline & To gather relevant factual information & \\
\hline & Like detailed and orderly teaching & \\
\hline & Structured and predictable & \\
\hline \multirow{7}{*}{$\begin{array}{l}\text { Right brain } \\
\text { preference }\end{array}$} & Prefer random things & \multirow{7}{*}{$\begin{array}{l}\text { 1. Use visual presentation } \\
\text { knowledge } \\
\text { 2. Encourage students to } \\
\text { communicate } \\
\text { 3. Combining practice learning } \\
\text { 4. Encourage direct experience } \\
\text { 5.Help students establish } \\
\text { connections }\end{array}$} \\
\hline & Like pictures, images, charts & \\
\hline & Love the whole language reading system & \\
\hline & $\begin{array}{l}\text { I would rather see or experience the } \\
\text { subject }\end{array}$ & \\
\hline & Like a natural learning environment & \\
\hline & Focus on external experience & \\
\hline & Have an open orientation & \\
\hline
\end{tabular}

(1) In the pre-class preparation stage, teachers shall learn the students' right and left-brain preferences, divide them into groups, choose corresponding teaching strategies and design relevant learning tasks according to different types of teaching contents.

(2) During class, teachers shall organize teaching activities in accordance with well-designed teaching tasks and corresponding strategies, and particularly guide the students according to their left and right brain preferences, thus to help them achieve whole brain learning. 
Jia, Fan, Hu, Liu, Chao, Zhang / Research on Teaching Strategies of Sports Translation Based on Neurocognitive Science.

(3) After the class, teachers shall arrange the corresponding assignments, review teaching activities based on the students' assignment status and performance in the class and adjust the teaching content and teaching methods in time.

\section{Sports translation teaching practice based on neurocognitive science}

In order to verify whether the whole brain teaching strategies proposed in this research is effective in practical teaching, a total of 102 students from Class One and Class Two of Grade 2016 of Sports English Major of Beijing Sport University are selected as subjects for the comparative experiment between traditional teaching and the whole brain teaching strategies teaching for the basketball program in "Sports English". The 5-point scale is used for scoring, with 1, 2, 3, 4 and 5 representing no, very few, general, more, and a lot respectively.

\section{a Whole brain teaching strategies design}

According to the basic knowledge composition necessary for sports translation and the characteristics of the basketball program, this study classifies and sets up the specific corpus for basketball according to the origin and development of basketball, the rules of basketball, the technique and tactics of basketball, and the introductions of NBA, FIBA, NCAA, and CBA. Students are grouped and assigned specific learning tasks, as detailed in Table 2 below (Légaré et al., 2011). Students are divided into groups and assigned specific learning tasks, as detailed in Table 2 below (Légaré et al., 2011).

Table 2

Application of Whole Brain Teaching Method in Classroom Teaching

\begin{tabular}{|c|c|c|}
\hline Topic & Corpus & Task \\
\hline $\begin{array}{l}\text { The origin and } \\
\text { development of } \\
\text { basketball }\end{array}$ & $\begin{array}{l}\text { 1. Introducing the English recording } \\
\text { material of the origin of basketball } \\
2 . \text { Introducing the English video } \\
\text { material for the development of } \\
\text { basketball }\end{array}$ & $\begin{array}{l}\text { Listen to recordings, watch videos, and } \\
\text { make records to repeat the origin and } \\
\text { development of basketball }\end{array}$ \\
\hline Basketball rules & $\begin{array}{l}\text { 1. Using basketball floor plan to } \\
\text { explain basketball rules and } \\
\text { basketball facilities } \\
\text { 2. Basketball Game Highlights Video } \\
\text { clips } \\
\text { 3. Text material on basketball rules in } \\
\text { textbooks }\end{array}$ & $\begin{array}{l}\text { 1. Record and report discussions on the } \\
\text { issued floor plan according to the } \\
\text { basketball rules explained by teachers } \\
\text { 2. Collect and record the rights } \\
\text { information of players, referees and } \\
\text { coaches through the competition video for } \\
\text { reporting and discussion } \\
\text { 3. According to the content of the } \\
\text { teaching materials, after class exercises } \\
\text { and translation }\end{array}$ \\
\hline $\begin{array}{l}\text { Basketball } \\
\text { Techniques and } \\
\text { Tactics }\end{array}$ & $\begin{array}{l}\text { 1. Basketball Sports Technical } \\
\text { Pictures } \\
\text { 2. Basketball Game Highlights Video } \\
\text { clips } \\
\text { 3. Text material on basketball } \\
\text { techniques and tactics in textbooks } \\
\end{array}$ & $\begin{array}{l}\text { 1. Record basketball tactics in the game } \\
\text { video, report the game process, and } \\
\text { conduct group discussions } \\
\text { 2. Complete reading exercises in } \\
\text { textbooks and translate some of the } \\
\text { content }\end{array}$ \\
\hline $\begin{array}{l}\text { NBA, FIBA, } \\
\text { NCAA, CBA } \\
\text { Introduction }\end{array}$ & $\begin{array}{l}\text { Students independently collect } \\
\text { materials and courseware about the } \\
\text { introduction of NBA, FIBA, NCAA, } \\
\text { and CBA. }\end{array}$ & $\begin{array}{l}\text { 1. Introduce NBA, FIBA, NCAA, CBA } \\
\text { using independently developed } \\
\text { courseware } \\
\text { 2.Listen to the teacher's feedback on the } \\
\text { student and record it }\end{array}$ \\
\hline
\end{tabular}


Jia, Fan, Hu, Liu, Chao, Zhang / Research on Teaching Strategies of Sports Translation Based on Neurocognitive Science.

$b$ Analysis of teaching effect

(1) Class time distribution

Table 3

Classroom Time Allocation

\begin{tabular}{lcc}
\hline Project & Experimental class & Control class \\
\hline Use Chinese to complete the learning task & 1.53 & 2.72 \\
Complete learning tasks in English & 3.7 & 3.25 \\
Lead class time & 4.82 & 1.34 \\
Attention & 4.36 & 3.07 \\
Participation & 3.56 & 2.09 \\
Student interaction & 3.48 & 2.36 \\
\hline
\end{tabular}

As shown by the classroom time allocation questionnaire results in Table 3, compared with the traditional classroom, the experimental class based on whole brain teaching strategies can complete most of the learning content in English. Meanwhile, as a large number of auxiliary teaching materials such as pictures and videos are used in the teaching process, the students pays more attention and get better understanding, and the frequency of interactive learning among students is also high.

(2) The training of abilities by course content

According to the survey results in Figure 7, as the experimental class is not rigidly limited to the grammar and word applications in the teaching process, but introduces a large number of pictures, videos, and audio materials, which have stimulated the cooperation of students' left and right brain functions. In addition, the audio and video playback in the teaching design trains students' listening abilities, and the design of the recording and summarizing of the learning content and textbook knowledge train their reading, writing and translation skills. Therefore, the listening, speaking, reading, writing and translating abilities of the experimental class students are higher than those of the control class.

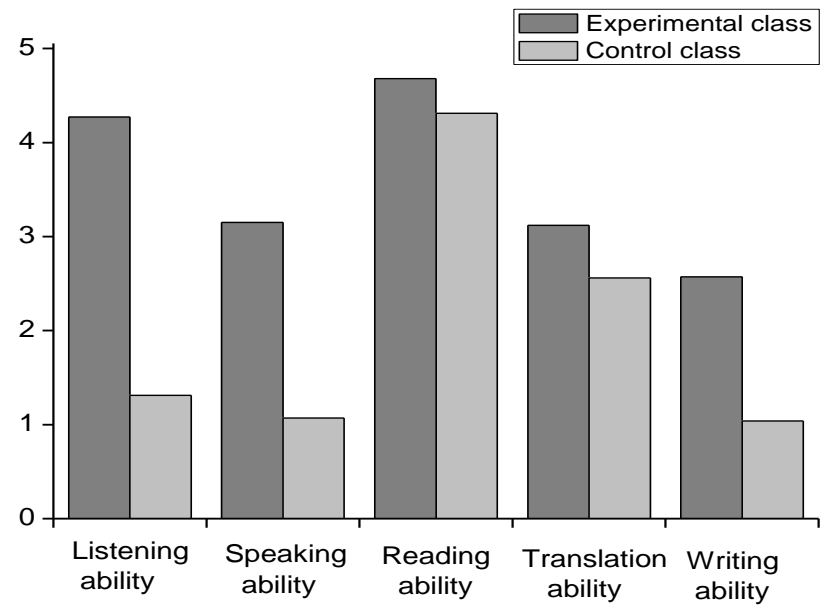

Figure 7. Curriculum content for the development of competence 


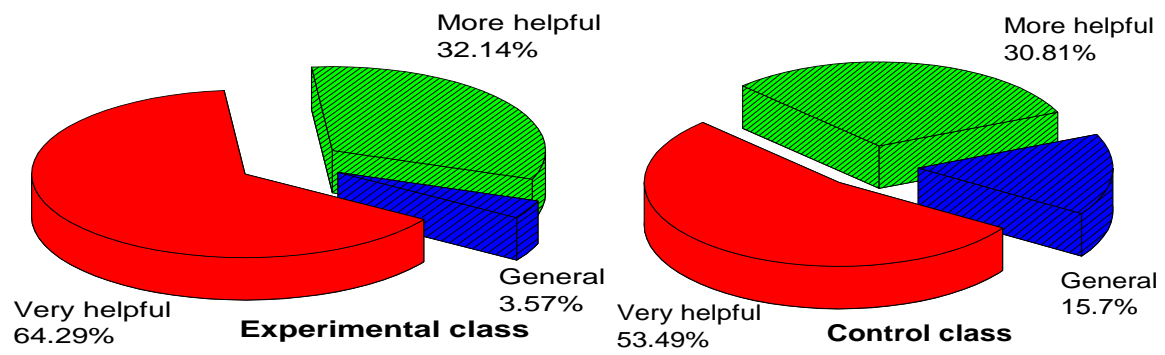

Figure 8. Help for learning purposes

Figure 8 shows the results of the survey on the help of course teaching for achieving the learning purposes. More than $95 \%$ of students in the experimental class think that the whole brain teaching strategies is very helpful for achieving their learning purposes, and only $3.57 \%$ of students think that the help is not too much. About $85 \%$ of students in the control class think that the traditional teaching pattern is very helpful for achieving their learning purposes, while up to $15.7 \%$ of students think that the help is not too much.

\section{Conclusion}

With sports translation teaching strategies as research objective, this paper attempts to study the teaching strategies of sports translation from the perspective of neurocognitive science based on the references home and abroad, in an effort to provide a new reference for experience translation teaching in China. The concrete conclusions are as follows.

(1) Based on the investigation and analysis of the status quo of sports translation talents in China, the present study finds that the quality of translation talents in China is yet to be improved and summarizes the knowledge composition necessary for sports translation.

(2) This study puts forward whole brain teaching strategies based on the whole brain theory and proposes four kinds of whole brain teaching strategies concerning sports translation.

(3) Combining whole brain teaching strategies and based on the design and implementation of Sports English course, this paper verifies that these teaching strategies have certain promoting effects in achieving the teaching goals of the course and improving students' abilities. 


\section{References}

Anderson, O. R. (1997). A neurocognitive perspective on current learning theory and science instructional strategies. Science Education, $\quad 81(1), \quad 67-89 . \quad$ http://dx.doi.org/10.1002/(SICI)1098237X(199701)81:1<67::AID-SCE4>3.0.CO;2-\#

Anderson, O. R. (2010). Some interrelationships between constructivist models of learning and current neurobiological theory, with implications for science education. Journal of Research in Science Teaching, 29(10), 1037-58. http://dx.doi.org/10.1002/tea.3660291004

Antonini, T. N., Kingery, K. M., Narad, M. E., Langberg, J. M., Tamm, L., \& Epstein, J. N. (2016). Neurocognitive and behavioral predictors of math performance in children with and without ADHD. Journal of attention disorders, 20(2), 108-118. http://dx.doi.org/10.1177/1087054713504620

Borsa, P. A., Wilk, K. E., Jacobson, J. A., Scibek, J. S., Dover, G. C., Reinold, M. M., \& Andrews, J. R. (2005). Correlation of range of motion and glenohumeral translation in professional baseball pitchers. The American journal of sports medicine, 33(9), 1392-1399. http://dx.doi.org/10.1177/0363546504273490

Carlo, C. (2013). Building a functional multiple intelligences theory to advance educational neuroscience. Frontiers in Psychology, 4(4), 950-950. http://dx.doi.org/10.3389/fpsyg.2013.00950

Esteban, M. A. (1980). Camus' art of translation: an unrecognized talent. Neophilologus, 64(3), 374-83. http://dx.doi.org/10.1007/BF01513831

Fissler, P., Kolassa, I. T., \& Schrader, C. (2015). Educational games for brain health: Revealing their unexplored potential through a neurocognitive approach. Frontiers in Psychology, 6, 1056-1056. http://dx.doi.org/10.3389/fpsyg.2015.01056

Göknar, E. (2004). My name is re (a) d: Authoring translation, translating authority. Translation Review, 68(1), 52-60. http://dx.doi.org/10.1080/07374836.2004.10523873

Grenier, M. (2007). Inclusion in physical education: from the medical model to social constructionism. Quest, 59(3), 298-310. http://dx.doi.org/10.1080/00336297.2007.10483554

Katan, D. (2009). Translation theory and professional practice: A global survey of the great divide. HERMESJournal of Language and Communication in Business, 22(42), 111-153.

Légaré, F., Borduas, F., Macleod, T., Sketris, I., Campbell, B., \& Jacques, A. (2011). Partnerships for knowledge translation and exchange in the context of continuing professional development. Journal of Continuing Education in the Health Professions, 31(3), 181-187. http://dx.doi.org/10.1002/chp.20125

Mckibbon, K. A., Lokker, C., Keepanasseril, A., Colquhoun, H., Haynes, R. B., \& Wilczynski, N. L. (2013). Whatiskt wiki: A case study of a platform for knowledge translation terms and definitions-descriptive analysis. Implementation Science, 8(1), 1-9. http://dx.doi.org/10.1186/1748-5908-8-13

Needham, J., GweiDjen, L., \& Porkert, M. (1975). Problems of translation and modernization of ancient Chinese technical terms. Annals of Science, 32(5), 491-502. http://dx.doi.org/10.1080/00033797500200411

Simonton, D. K. (2008). Scientific talent, training, and performance: Intellect, personality, and genetic endowment. Review of General Psychology, 12(1), 28-46. http://dx.doi.org/10.1037/1089-2680.12.1.28 
Jia, Fan, Hu, Liu, Chao, Zhang / Research on Teaching Strategies of Sports Translation Based on Neurocognitive Science.

Singh, R. K. (1993). Teaching translation and interpreting: Training, talent, and experience by cay Dollerup; Anne Loddegaard. International Journal on World Peace, 10(3), 113-120. http://dx.doi.org/10.7202/004161ar

Timothy, D. (2006). Translation and the individual talent: The splendid isolation of our translators of Russian Classics. Translation Review, 71(1), 37-40. http://dx.doi.org/10.1080/07374836.2006.10523933

The Canadian Association for Population Therapeutics /Association Canadienne pour la Thérapeutique des Populations presents: Taking Action on Real World Evidence: From Analysis to Impact, Journal of Population Therapeutics and Clinical Pharmacology, 25(2): e33-e62, DOI: 10.22374/1710-6222.25.2.6

Weaver, M. A., \& Chelladurai, P. (1999). A mentoring model for management in sport and physical education. Quest, 51(1), 24-38. http://dx.doi.org/10.1080/00336297.1999.10491666 